http://dx.doi.org/10.35381/racji.v5i8.573

\title{
El derecho a la verdad como mecanismo idóneo de reparación integral
}

The right to the truth as an ideal mechanism for integral reparation

Pablo Andrés Padrón-Espinoza

pablo.padron@psg.ucacue.edu.ec

Universidad Católica de Cuenca, Cuenca

Ecuador

https://orcid.org/0000-0001-9104-1657

Cecilia Ivonne Narváez-Zurita

inarvaez@ucacue.edu.ec

Universidad Católica de Cuenca, Cuenca

Ecuador

https://orcid.org/0000-0002-7437-9880

Marcelo Alejandro Guerra-Coronel

mguerrac@ucacue.edu.ec

Universidad Católica de Cuenca, Cuenca

Ecuador

https://orcid.org/0000-0001-8526-773X

Juan Carlos Erazo-Álvarez

jcerazo@ucacue.edu.ec

Universidad Católica de Cuenca, Cuenca

Ecuador

https://orcid.org/0000-0001-6480-2270

Recibido: 15 de noviembre de 2019

Aprobado: 16 de diciembre de 2019

\section{RESUMEN}

Las graves violaciones a derechos humanos que han ocurrido en la región latinoamericana y en el Ecuador fueron el punto de partida para que el derecho a la verdad surja en este hemisferio como un freno a estos atropellos, con la finalidad de que las voces de las víctimas sean escuchadas por los gobiernos de turno, sobre quienes pesa la obligación de investigar la verdad de lo ocurrido. El objetivo que 
persigue este artículo consiste en establecer que el derecho a la verdad es el medio idóneo de reparación integral en favor de las víctimas de violaciones graves a derechos humanos. La metodología que se utilizó es de tipo descriptiva - Ex post factos, por cuanto se analizarán definiciones de autores que han tratado sobre el tema; así como los pronunciamientos emitidos por la Corte Interamericana de Derechos Humanos y por la Corte Constitucional del Ecuador.

Descriptores: Derecho a la verdad; Reparación integral; Víctimas; Estado; violaciones; Derechos humanos.

\begin{abstract}
The serious human rights violations that have occurred in the Latin American region and in Ecuador were the starting point for the right to the truth to emerge in this hemisphere as a brake on these abuses, in order for the voices of the victims be heard by the governments of the day, on whom the obligation to investigate the truth of what happened weighs. The objective of this article is to establish that the right to the truth is the ideal means of integral reparation for the victims of serious human rights violations. The methodology used is of a descriptive type - Ex post factos, since definitions of authors who have dealt with the subject will be analyzed; as well as the pronouncements issued by the Inter-American Court of Human Rights and by the Constitutional Court of Ecuador.
\end{abstract}

Descriptors: Right to the truth; Integral repair; Victims; Estate; Violations; Human rights.

\title{
INTRODUCCIÓN
}

La existencia del Derecho Constitucional por su naturaleza intrínseca es de importancia primordial en los países democráticos que buscan el bien común de sus individuos, en el caso ecuatoriano, la Constitución de la República al ser garantistas de derechos reconoce ampliamente el efectivo goce y ejercicio tanto de los derechos constitucionales como de derechos humanos instaurados en instrumentos internacionales debidamente ratificados y aceptados, siendo imperante que exista en su estructura mecanismos de reparación integral con el fin de permitir a los ciudadanos ejercer sus derechos cuando estos hubiesen sido transgredidos, por lo tanto, es un derecho fundamental que obliga al Estado a perseguir su procedimiento y supervisar su 
cumplimiento (Macassi, 2001). El derecho a la verdad por su parte también es un derecho humano y constitucional que busca brindar una respuesta sobre lo sucedido a las víctimas de graves violaciones de derechos humanos (Tamayo Vásquez \& Pino Loza, 2019).

El derecho a la verdad llega a convertirse en una medida de reparación hacia las víctimas, el reconocimiento y ejercicio de este derecho constituye un medio de reparación dependiendo del caso en concreto, brindando el Estado de esta manera una expectativa justa a las victimas (Caso Heliodoro Portugal vs. Panamá, 2008). E derecho a la verdad parecería ser de reciente aparición en el hemisferio latinoamericano, no obstante, en las últimas cuatro décadas se ha posicionado cada vez más en las normas internas de los Estados por cuanto existe la necesidad de ser desarrollado y aplicado a través del Sistema Interamericano de Derechos Humanos debido a las graves violaciones de derechos humanos que han ocurrido en este continente, ya sea, por el quebrantamiento de la democracia, por conflictos armados internos o por acciones subversivas de grupos paramilitares.

Este derecho surgió para frenar estas vulneraciones evitando que la impunidad impere y que las víctimas de estos delitos tengan derecho a saber la verdad de lo que ocurrió, la identidad de los responsables y la suerte de los suyos, siendo responsabilidad del Estado brindar estas respuestas por medio de investigaciones que permitan judicializar y sancionar a los responsables (Guzmán Chávez, 2019). En el desarrollo de este artículo se realizará un estudio con el fin de valorar el derecho a la verdad como una medida adecuada de reparación integral en favor de las víctimas de graves violaciones a derechos humanos, se analizará la importancia de su surgimiento en el continente y se determinará quienes son considerados como víctimas de los delitos de lesa humanidad.

Finalmente se investigará sobre la creación de las comisiones de la verdad en la región, para ello se analizan casos basados en la experiencia de América Latina y Ecuador donde el derecho a la verdad fue aplicado y utilizado con el fin de brindar a las víctimas 
una respuesta estatal como un mecanismo de reparación integral no monetario, más bien sensitivo ante el cometimiento de delitos que atentaron contra derechos humanos.

\section{DESARROLLO}

\section{El derecho a la verdad un freno a violaciones de derechos humanos}

Se piensa que el derecho a la verdad es contemporáneo, por cuanto ha sido desarrollado por medio de resoluciones de la Corte Interamericana de Derechos Humanos, las cuales han servido de base para su perfeccionamiento, enlazando disposiciones de la Convención Americana, puntualmente las establecidas en los artículos ocho y veinte y cinco (Poveda, 2014); por lo que, el origen de este derecho en América Latina fue necesario y emergente debido a que se produjeron varios quebrantamientos de la democracia que trajeron consigo conflictos armados internos y guerras civiles, los cuales trataban de ser controlados por los gobiernos de turno quienes como respuesta a estos hechos declaraban el estado de emergencia en su país, producto de lo cual ocurrían varias violaciones a derechos humanos por parte de agentes estatales quienes con la excusa de cumplir sus funciones se extralimitaban contra el pueblo (Comisión Interamericana de Derechos Humanos, 2014).

El origen del derecho a la verdad nace de las primeras decisiones del Sistema Interamericano específicamente en lo referente a los delitos de desaparición forzada, al pensar que se debía considerar como víctimas a los familiares de las personas desaparecidas por cuanto su derecho era el saber cuál fue el destino de sus familiares, la suerte con la que corrieron y la posible localización e identificación de sus restos (Durán, 2008). El Sistema Interamericano de Derechos Humanos desarrollo el derecho a la verdad, consiguiendo que el mismo surja como contraposición a las graves violaciones de derechos humanos y la impunidad que se buscaba por parte de los responsables de estos hechos, impidiendo de este modo que las víctimas accedan a la verdad y por lo tanto a la justicia (Pedraza, 2008). 
El derecho a saber la verdad es conceptualizado como una medida de reparación en favor de las víctimas y/o sus familiares que pretenden saber los por menores de lo sucedido, como por ejemplo el lugar donde ocurrieron los hechos, cuando sucedieron, las razones para que ese resultado se haya producido, la identificación de los responsables y su debida sanción, todas estas circunstancias una vez definidas y descubiertas son medios de reparación fundamentales en favor de las víctimas de estas violaciones, obligación que recae sobre el Estado (Comisión Interamericana de Derechos Humanos, 2014). El derecho a la verdad está reconocido por la Constitución de la República del Ecuador en su artículo 78 como un derecho fundamental y medio de reparación no pecuniario sino más bien inmaterial.

La obligación de investigar la verdad de lo oculto sobre violaciones de derechos humanos recae sobre los Estados quienes tienen la responsabilidad de revelar la verdad de los hechos a los familiares de las víctimas y a la sociedad en general (Méndez, 2004); siendo el Estado el obligado principal de investigar sobre lo sucedido, al respecto González (2008) argumenta “...pesa sobre los Estados el deber de investigar lo verdaderamente ocurrido en casos de graves violaciones a los derechos humanos". (p.441)

Por lo tanto, el derecho a la verdad es la vía adecuada por medio de la cual las victimas pueden hacer válido su derecho a descubrir la verdad a través de una investigación adecuada, tarea que es responsabilidad del Estado por medio de sus organismos que tienen la obligación de brindar una respuesta debida. En la actualidad esta responsabilidad pesa sobre los gobiernos de turno a quienes les compete investigar lo sucedido en épocas anteriores donde imperaba la dictadura y los civiles eran sancionados por medio de políticas militares y policiales vulnerándose de esta manera sus derechos humanos fundamentales.

Lo que las víctimas de estos delitos buscan es saber la verdad de lo sucedido, no se persigue una reparación económica, por lo que, la única medida de reparación integral que sería adecuada en este tipo de casos es que el Estado les brinde una respuesta 
verdadera, por medio de este derecho se busca saber lo que ocurrió, el paradero de las víctimas o sus restos.

Las graves violaciones a derechos humanos así como los crímenes de lesa humanidad deben ser judicializados con la finalidad de que el resultado sea satisfactorio para las víctimas quienes buscan como medio de reparación integral que se llegue hacer justicia a través de la verdad (Caicedo D. , 2014). Frente a violaciones graves de derechos humanos el concepto de víctima no solo se circunscribe a la persona quien recibió el agravio, sino que, la conceptualización de víctima se extiende más allá considerando a sus familiares e incluso a la sociedad, si bien los familiares son los primeros interesados en saber la suerte de los suyos; sin embargo, también se considera como víctima a la sociedad por cuanto es de interés colectivo de un pueblo el saber la razón del cometimiento de estos hechos y que los mismos sean esclarecidos y judicializados por cuanto la zozobra de que los mismos actos se vuelvan a repetir es de sentir general.

Al respecto, la Corte Interamericana de Derechos Humanos (CIDH), estableció que el Estado había vulnerado el derecho a la verdad de la víctima, de sus familiares y de la sociedad en su conjunto, realizando una diferenciación especifica entre el carácter colectivo y el carácter individual, a través de esta diferenciación se establece la razón del por qué la sociedad también es otra víctima de estos delitos que busca el descubrimiento de la verdad, configurándose en una forma de reparación (Caso Bámaca Velásquez Vs. Guatemala, 2000); como se puede apreciar este derecho en sus inicios fue creado con la finalidad de que los familiares de las victimas conozcan la verdad de la suerte con la que corrieron los miembros de su familia de quienes se desconocía su paradero (Comite Internacional de la Cruz Roja, 2012).

En lo posterior esta definición sobre el derecho a la verdad amplía sus horizontes dando origen a una concepción mucho más desarrollada desde un punto de vista individual y colectivo pudiendo enunciar que el derecho a la verdad individual se refiere al interés de saber la verdad por parte de los familiares de la víctima; $y$, un derecho a la verdad colectivo que se relaciona con el derecho que tiene la sociedad en conocer la verdad de 
los hechos, las razones y circunstancias que conllevaron a su cometimiento, pretendiendo que la finalidad de este derecho se convierta en una garantía de no repetición de los mismos (Comisión Colombiana de Juristas, 2007).

\section{Verdad y reparación, una visión desde la experiencia ecuatoriana}

El Estado ecuatoriano ha sido demandado ante la $\mathrm{CIDH}$ por presuntas violaciones graves a derechos humanos, casos en los cuales el derecho a la verdad ha sido exigido por las víctimas como una medida de reparación, por lo que a continuación se estudiara de manera cronológica los casos más relevantes sobre el tema, desde la experiencia ecuatoriana; así como también, se analizara la sentencia $N^{\circ}$ 068-18-SEP-CC emitida por la Corte Constitucional del Ecuador en lo referente al tema que está siendo analizado.

A partir de lo manifestado, se inicia con el caso conocido como Tibi Vs. Ecuador el cual fue presentado por la Comisión IDH ante la Corte IDH, por considerar que el Estado ecuatoriano violento varios derechos del Señor Daniel David Tibi, la relación circunstancial de los hechos relata que el señor Tibi fue detenido sin orden judicial alguna por agentes de la policía en la ciudad de Quito, mientras conducía su vehículo en el cual se dedicaba a comercializar piedras preciosas, la detención ocurrió el día 27 de septiembre de 1995, luego de haber sido arrestado fue trasladado hasta la ciudad de Guayaquil siendo detenido ilegalmente por 28 meses, tiempo en el cual fue torturado con la finalidad que se declare culpable por el delito de narcotráfico por el cual lo acusaban, además de aquello le fueron incautados bienes de su propiedad valorados en un millón de francos franceses, los cuales una vez que recuperó su libertad no le fueron devueltos (Caso Tibi Vs. Ecuador, 2004).

Dentro de este caso, los familiares y representantes del señor Tibi fundamentados en el derecho a la verdad colectivo, solicitaron como medida de reparación entre otras que el Estado investigue, determine responsabilidades, juzgue su actuar y emita sanciones a los causantes de las violaciones a los derechos humanos del señor Tibi, así como a 
todos aquellos que permitieron de manera dolosa u omisiva que la impunidad prevalezca, solicitaron además que el resultado de la investigación sea divulgado públicamente para que la sociedad pueda conocer la verdad (Caso Tibi Vs. Ecuador, 2004).

La Corte dentro de este caso, se basó en el precedente emitido dentro del caso de los Hermanos Gómez Paquiyauri, donde se estableció que los familiares y las victimas de violaciones a los derechos humanos tienen derecho a conocer la verdad, por lo tanto dentro del presente caso los familiares del señor Tibi tienen derecho a que se les informe sobre las acutaciones que se dan dentro del proceso, considerando por lo tanto que el derecho a la verdad puede llegar a ser un medio de reparación adecuada (Caso de los Hermanos Gómez Paquiyauri Vs. Perú, 2004).

En el caso Tibi, la Corte por unanimidad declaró que el Estado ecuatoriano vulnero varios derechos contemplados en la Convención Americana de Derechos Humanos, por estas consideraciones se dispuso entre otras medidas de reparación que: "El Estado debe, en un plazo razonable, investigar efectivamente los hechos del presente caso, con el fin de identificar, juzgar y sancionar a todos los autores de las violaciones cometidas en perjuicio del señor Daniel Tibi" (Caso Tibi Vs. Ecuador, 2004, p.111). Se estableció como una medida de reparación en favor de las victimas el derecho de que se investiguen los hechos para descubir la verdad, debiendo identificarse, juzgar y sancionar a los responsables.

A continuación, se analiza el caso Zambrano Vélez y otros Vs. Ecuador, el mismo que se enmarca en una supuesta ejecución extrajudicial cometida por miembros de las Fuerzas Armadas y de la Policía Nacional del Ecuador durante un operativo realizado el 06 de marzo de 1993 en la ciudad de Guayaquil en el marco de un estado de emergencia, producto de lo cual los señores Wilmer Zambrano Vélez, José Miguel Caicedo Cobeña; y, Segundo Olmedo Caicedo Cobeña pierden su vida al haber sido ejecutados extrajudicialmente (Caso Zambrano Vélez y otros Vs. Ecuador, 2007). 
Estos hechos no fueron investigados de manera adecuada por parte del Estado ecuatoriano pese a que ya habían transcurrido varios años, no se logró identificar a los responsables quienes gozaban de impunidad, por lo que la Comisión IDH solicito a la Corte que se declare como responsable internacionalmente al Estado ecuatoriano por haber violado derechos como el derecho a la vida, el derecho a la protección judicial y por haber suspendido garantías inadecuadamente, solicitando que se determinen medidas de reparación en favor de las víctimas y sus familiares (Caso Zambrano Vélez y otros Vs. Ecuador, 2007).

Hay que destacar que dentro de este caso el Estado ecuatoriano reconoció que el derecho a la verdad ha sido quebrantado por irresponsabilidad de su parte, el cual se comprometió a reconocer y tutelar este derecho a través de la Comisión de la Verdad creada para el efecto, la misma que era la encargada de investigar los hechos con la finalidad de que se inicie un proceso penal para que los responsables sean sancionados, asegurando que de esta manera el derecho a la verdad de las victimas sea resarcido. (Caso Zambrano Vélez y otros Vs. Ecuador, 2007).

La Corte por unanimidad le dispuso al Estado ecuatoriano que utilice todos los medios disponibles y emprenda de inmediato todas las diligencias necesarias para llevar adelante una investigación adecuada y oportuna con el fin de identificar, localizar y enjuiciar a los responsables para que sean sancionados por el delito de ejecución extrajudicial en perjuicio de las víctimas, evitando que hechos similares vuelvan a ocurrir (Caso Zambrano Vélez y otros Vs. Ecuador, 2007). Con relación al derecho a la verdad se ordenó que: "...el Estado debe satisfacer el derecho a la verdad de los familiares de las víctimas y asegurar que ellos tengan pleno acceso y capacidad de actuar en todas las etapas e instancias de dichas investigaciones y procesos" (Caso Zambrano Vélez y otros Vs. Ecuador, 2007, p.48). De esta manera se garantizó a los familiares de las victimas el acceso a la justicia para que a través de ella se descubra la verdad de lo que pasó. 
Se aborda a continuación, el caso conocido como Albán Cornejo y otros Vs. Ecuador en el cual los familiares de la víctima buscaban saber la verdad de lo ocurrido con su hija, no obstante, la Corte solo dispuso reparaciones pecuniarias, disculpas públicas, programas de capacitación y formación sobre el derecho de los pacientes, lamentablemente no se emitió medida de reparación alguna que precautele el derecho a saber la verdad a pesar de que los familiares de la víctima así lo requerían, este caso fue de igual manera llevado ante la Corte Interamericana, la demanda se instauró en contra del Hospital Metropolitano por un supuesto ocultamiento de información sobre el tratamiento y la futura muerte de la señorita Albán Cornejo, por cuanto dicho hospital encubrió la identidad de los médicos responsables que intervinieron previo al fallecimiento de la víctima (Caso Albán Cornejo y otros Vs.Ecuador, 2007). Toda la información reclamada fue considerada como valiosa para el esclarecimiento de los hechos que conllevaron al fatídico resultado, razón por la cual los padres de la víctima alegaron su derecho a la verdad, para saber qué fue lo que realmente ocurrió con su hija en dicha dependencia de salud.

Como cuarto antecedente se analiza lo referente a la sentencia $N^{\circ}$ 068-18-SEP-CC emitida por la Corte Constitucional del Ecuador, en la cual se declaró que el derecho a la verdad ha sido vulnerado, este caso se basa en los hechos ocurridos en el Hospital "Delfina Torres de Concha" del cantón Esmeraldas, institución pública en la cual una menor edad de apenas 18 días de nacida estaba siendo intervenida quirúrgicamente y a quien se le realizó una transfusión de sangre para lo cual el departamento de Trabajo Social del Hospital solicito a la Cruz Roja de Esmeraldas la sangre para dicho procedimiento, producto del cual al parecer la menor había sido contagiada de $\mathrm{VIH}$, por lo cual el padre de la menor presento una denuncia en contra del hospital el 03 de octubre de 2012 (Sentencia No 068-18-SEP-CC, 2018).

La investigación estaba dirigida por la Abg. Karen Duque Jironza, Fiscal de Violencia de Género $\mathrm{N}^{\circ} 1$ de Esmeraldas, por el presunto delito de lesiones a través del contagio de una enfermedad incurable por sustancias que alteran la salud, contemplado en el 
artículo 469 del Código Penal derogado que establecía "La pena será de prisión de dos a cinco años, cuando dichas sustancias hubieren causado una enfermedad cierta o probablemente incurable, o una incapacidad permanente para el trabajo personal, o la pérdida absoluta, o inutilización de un órgano" (Corporación de Estudios y Publicaciones, 2012, p.222).

La Señora Fiscal el día 08 de octubre de 2015, solicito la desestimación de la denuncia y el archivo de la misma, considerando que una vez que se realizaron las diligencias investigativas pertinentes no existieron elementos suficientes para iniciar una instrucción fiscal en contra de los presuntos responsables, solicitud la cual fue aceptada por la Unidad Judicial Penal de Esmeraldas el 19 de noviembre de 2015, ordenando el archivo de la investigación, por lo que, el padre de la víctima presento una acción de protección contra la decisión de archivo de indagación previa, la garantía jurisdiccional fue negada por la Unidad Judicial Penal de Esmeraldas insinuando que la vulneración de los derechos constitucionales reclamados no han sido probados, a lo cual se interpuso la apelación correspondiente alegando que tanto la solicitud de desestimación como la del archivo de la investigación vulneran derechos constitucionales de la menor (Sentencia No 068-18-SEP-CC, 2018).

El recurso de apelación fue inadmitido por parte de la Sala Única Multicompetente de la Corte Provincial de Justicia de Esmeraldas, bajo el fundamento de que la acción de protección no procede en contra de providencias o decisiones judiciales, acto seguido se presentó una acción extraordinaria de protección en contra de la sentencia dictada por la Sala Única Multicompetente de la Corte Provincial de Justicia de Esmeraldas, dentro de la acción de protección № 2015-02333 (Sentencia № 068-18-SEP-CC, 2018). Una vez que la Corte Constitucional tuvo competencia sobre el presente caso y al determinar que tanto la sentencia de primera como de segunda instancia vulneran el derecho a la motivación, se centró en resolver el problema jurídico enmarcado en que si la solicitud de desestimación y archivo de la indagación previa fiscal, vulneraba el derecho a la verdad, contemplado en el artículo 78 de nuestra Constitución que guarda 
conexidad con la tutela judicial efectiva, establecida en el artículo 75 (Sentencia N ${ }^{\circ}$ 06818-SEP-CC, 2018).

Para una mejor solución a este problema juridico, la Corte se baso en el predente jurispurdencial emitido en la Sentencia N. ${ }^{\circ} 111-16-S E P-C C ~(2016)$ que consideraba que "...el conocimiento de la verdad de los hechos, como elemento integrante y sustancial del derecho a la reparación integral, constituye una garantía a favor de las víctimas de infracciones penales y/o sus familiares y la sociedad en general" (p.7). El derecho a la verdad tiene como finalidad que un caso sea investigado para determinar responsabilidades y sancionar a sus actores, constituyéndose como una garantía inherente a las víctimas de infracciones penales y a sus familias, este derecho tiene íntima relación con la tutela judicial efectiva y el debido proceso de conformidad con lo dispuesto en el numeral 6 del artículo 11 de la norma suprema (Sentencia N 068-18SEP-CC, 2018).

En la presente sentencia se consideró que al existir una falta de investigación diligente por parte de la fiscal quien consideró que la investigación debía ser archivada se estaba impidiendo que la víctima obtenga una sentencia a su favor y por ende la correspondiente reparación integral, vulnerando de esta manera el derecho a la verdad y a la tutela judicial efectiva, la reparación integral es un derecho constitucional que pretende reparar los derechos que fueron vulnerados por medio de medidas que logren volver las cosas al estado anterior o uno similar previo a la vulneración de un derecho, al respecto la Corte manifiesta que: "...los jueces constitucionales se encuentran en la obligación ante una vulneración de derechos constitucionales, de dictar medidas de reparación integral que no solo consideren la vulneración en sí, sino además la condición de las víctimas de la vulneración de derechos (Sentencia № 068-18-SEP-CC, 2018, p.54).

La Corte en su sentencia declaró la vulneración al derecho a la verdad y por ende el derecho a la tutela judicial efectiva, dejando sin efecto tanto la resolución emitida por la Sala Penal y la sentencia dictada por la Unidad Judicial Penal; así también se dejo sin 
efecto la solicitud de desestimación y archivo solicitado por la Señora Fiscal, ordenando que se inicie una nueva investigación (Sentencia Nº68-18-SEP-CC, 2018). En la sentencia analizada también se ordenó otros tipos de medidas de repración.

\section{Las comisiones de la verdad en Latinoamérica: experiencia ecuatoriana}

Las comisiones de la verdad fueron creadas con la finalidad de realizar una investigación de carácter no judicial en contra de prácticas abusivas cometidas en el pasado, son organismos temporales establecidos por los gobiernos de turno, destinados a investigar sobre las violaciones cometidas en contra de derechos humanos, emitir un informe final y a formular recomendaciones, si bien las comisiones no tienen el poder de enjuiciar pueden recomendar que se enjuicie a quienes determinaron como responsables y pueden compartir su información con la fiscalía (Hayner, 2006).

Frente a delitos que vulneren derechos humanos, se puede adoptar cualquier medida administrativa y judicial para que la investigación continúe y poder así identificar a los responsables y sancionarlos, garantizando a los familiares de las victimas el acceso a la investigación y por lo tanto a la justicia en todas sus etapas y grados, debiendo ser publicado el resultado de la investigación para que la sociedad conozca la verdad (Caso de los Hermanos Gómez Paquiyauri Vs. Perú, 2004); las comisiones de la verdad son las encargadas de adoptar cualquier medio sea judicial o administrativo para investigar lo sucedido, teniendo contacto directo con las víctimas o sus familiares para de esta manera realizar una investigación minuciosa partiendo del relato de los hechos por parte de los mismos afectados. Las comisiones han aportado pruebas concretas que han servido de ayuda para las investigaciones, permitiendo superar conflictos (Bernales, Scielo:, 2016).

Como un frente a las graves violaciones de derechos humanos en Latino América se crearon comisiones sobre la verdad las cuales han sido un elemento importante para desvelar lo encubierto por las propagandas oficialistas con el fin de procurar que los 
casos de graves violaciones no sean descubiertos, ya que en los países del sur en los últimos cuarenta años se experimentaron conflictos internos, situación que fue aprovechada por estrategas de los Estados Unidos de Norteamérica quienes procuraron que la democracia latinoamericana se vea vulnerada y poder así ceder el poder a dictaduras militares (Cuya y Menschenrechtszentrum, S/F).

Una vez que los Estados recuperaron su democracia surgieron varias hipótesis como por ejemplo el que hacer con los responsables de todas las vulneraciones a los derechos humanos, la respuesta que se les debía dar a las víctimas, la manera de buscar el restablecimiento de la paz interna sin que previamente se haga justicia, ya que antes de que los regímenes militares abandonen el poder trataron de borrar todo tipo de sospecha y evidencia sobre su responsabilidad para no ser enjuiciados posteriormente por sus actos, emitiendo leyes como la ley de obediencia debida, ley de caducidad, ley de amnistía, etc. (Cuya y Menschenrechtszentrum, S/F); cuando los regímenes totalitarios fueron superados surgió la imperante necesidad de que la verdad y la justicia se conecten entre sí, para que de este modo los hechos punibles puedan ser conocidos por medio de la verdad y sancionados por medio de la justicia (Maculan y Pastor, 2013).

En la década de los años ochenta, las leyes de impunidad se propagaron en Centro y Suramérica, dichas leyes fueron creadas con la finalidad de conseguir amnistía de lo causado, la prescripción de los hechos y el perdón de lo ocasionado, es decir, el propósito de esta creación era el de evitar a toda costa que las violaciones cometidas por los agentes estatales sean investigadas, evadiendo su responsabilidad y castigo (Ventura, 2005). En el mundo existen alrededor de treinta y cuatro comisiones de la verdad de las cuales catorce están establecidas en Latinoamérica, siendo las comisiones de Argentina, Chile, El Salvador, Guatemala, Perú y Uruguay las que han demostrado desarrollar esfuerzos importantes para superar las graves vulneraciones de las cuales han sido víctimas sus ciudadanos, inclusive en este continente se han creado comisiones con el propósito de emitir reflexiones (Fajardo, 2012). 
La comisión de la verdad en Ecuador fue creada durante la presidencia de Rafael Correa Delgado, el 03 de mayo de 2007, mediante Decreto Ejecutivo $\mathrm{N}^{\circ} 305$, con la finalidad de investigar los agravios contra derechos humanos cometidos por miembros de las Fuerzas Armadas, elemento de la Policía Nacional y demás organismos estatales que hayan tenido vínculos con el tema de defensa nacional y seguridad interna durante el período comprendido desde el año de 1984 hasta el año 2008, enfocándose específicamente contra delitos como tortura, privación ilegal, violencia sexual, desaparición forzada, delitos contra la vida y ejecución extrajudicial (Rivera, 2011); la comisión de la verdad estuvo integrada solo por personas de nacionalidad ecuatoriana, inclusive muchos de los comisionados fueron personas que habían sido víctimas directas de violaciones de derechos humanos, el informe final de la Comisión de la Verdad fue entregado el 7 de junio de 2010 (Caicedo D. , 2014).

En el informe final entre las conclusiones se indicó que en el gobierno de León Febres Cordero fue donde se registró un mayor número de víctimas de violaciones graves contra los derechos humanos en el Ecuador, dando un resultado de 311 personas de las 456 víctimas totales, es decir, que en el gobierno del Partido Social Cristiano presidido por Febres Cordero se vulneraron derechos humanos a más de la mitad de las víctimas totales (68\%) que han sufrido este tipo de agravios (Caicedo D. , 2014). En el Ecuador, así como en Bolivia, Paraguay y Uruguay no existe registro alguno que denote que un caso de violación a los derechos humanos ha sido judicializado a pesar de haberlo intentado, lo cual no sucede con países como Argentina que si registra procesos en los cuales se ha logrado imponer sanciones a los responsables de estos delitos, en el caso de Chile, el proceso que mayor connotación tuvo fue el proceso seguido en contra de Augusto Pinochet, donde el Juez chileno Juan Guzmán condeno al ex dictador Augusto Pinochet a arresto domiciliario por secuestro y asesinato (Délano, 2004).

En Perú se ha conseguido un poco más de relevancia en este sentido ya que si se ha llegado a judicializar casos como por ejemplo los de Barrios Altos; y, La Cantuta entre 
otros. Colombia en su caso tan solo ha logrado llevar casos de violaciones a derechos humanos ante la Corte IDH (Caicedo, 2014), en el cuadro 1 se puede observar de manera cronológica las denominaciones de las comisiones de la verdad instauradas en

\section{Cuadro 1}

Comisiones de la verdad en América Latina

\begin{tabular}{|c|c|c|}
\hline País & $\begin{array}{l}\text { Año de } \\
\text { creación }\end{array}$ & Nombre de la Comisión \\
\hline Bolivia & 1982 & $\begin{array}{l}\text { Comisión Nacional de } \\
\text { Investigación de Desaparecidos } \\
\text { Forzados }\end{array}$ \\
\hline Argentina & 1983 & $\begin{array}{l}\text { Comisión Nacional sobre } \\
\text { la Desaparición de Personas }\end{array}$ \\
\hline Chile & 1990 & $\begin{array}{l}\text { Comisión Nacional de Verdad } \\
\text { y Reconciliación }\end{array}$ \\
\hline El Salvador & 1992 & Comisión de la Verdad \\
\hline Haití & 1995 & $\begin{array}{l}\text { Comisión Nacional de Verdad y de } \\
\text { Justicia }\end{array}$ \\
\hline Guatemala & 1997 & $\begin{array}{l}\text { Comisión para el Esclarecimiento } \\
\text { Histórico }\end{array}$ \\
\hline Uruguay & 2000 & Comisión para la Paz \\
\hline Perú & 2000 & $\begin{array}{l}\text { Comisión de la Verdad y la } \\
\text { Reconciliación }\end{array}$ \\
\hline Panamá & 2001 & Comisión de la verdad \\
\hline Paraguay & 2003 & Comisión de Verdad y Justicia \\
\hline Colombia & 2005 & $\begin{array}{l}\text { Comisión Nacional de Reparación } \\
\text { y Reconciliación }\end{array}$ \\
\hline Ecuador & 2007 & Comisión de la Verdad \\
\hline Honduras & 2009 & $\begin{array}{l}\text { Comisión de la Verdad y la } \\
\text { Reconciliación }\end{array}$ \\
\hline Brasil & 2012 & Comisión Nacional de la Verdad \\
\hline
\end{tabular}

Fuente: (Bernales, 2016).

Se concluye que la experiencia de las comisiones de la verdad en la región, a excepción, de la Comisión Nacional sobre la Desaparición de Personas de la Argentina ha sido escasa y en algunos casos nula como en el caso ecuatoriano, pese a que existen casos como el de los hermanos Restrepo que denotan una vulneración a los derechos fundamentales y humanos de las víctimas, sus familiares y de la sociedad ecuatoriana en su conjunto que reclama saber la verdad y el paradero de sus restos.

Existe además en el Ecuador el caso por desaparición forzada de la profesora Consuelo Benavides, quien el 04 de diciembre de 1985 fue arrestada sin una orden judicial para 
fines investigativos por presuntas actividades subversivas ligadas con el grupo "Alfaro Vive Carajo", quien luego fue torturada y asesinada por agentes de la Infantería Naval Ecuatoriana en la Quinindé, durante la presidencia de León Febres Cordero, este caso fue puesto en conocimiento de la Corte IDH ante lo cual el Estado ecuatoriano reconoció su responsabilidad internacional por haber violentado varios derechos protegidos por la Convención Americana sobre Derechos Humanos, en perjuicio de Consuelo Benavides Cevallos, en lo referente al derecho a la verdad el agente estatal puso en conocimiento de la Corte que el nombre de la víctima ha sido reivindicado a través de todos los medios de prensa radiodifusores y escritos del Ecuador, por cuanto se ha hecho público la lucha por saber la verdad de lo ocurrido, a pesar, de haber transcurrido varios años de impunidad (Caso Benavides Cevallos Vs. Ecuador, 1998).

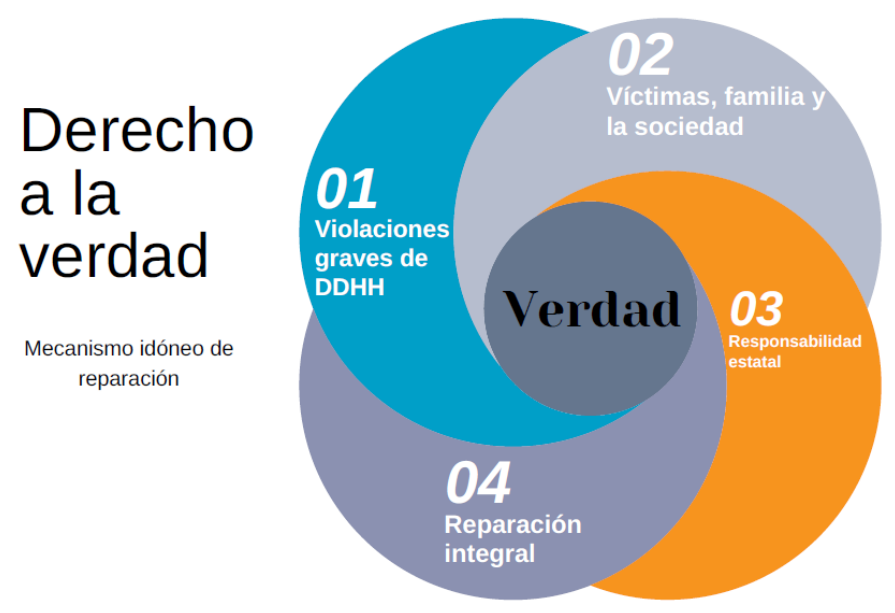

Figura 1. Elementos estructurales del derecho a la verdad

\section{METODOLOGÍA}

La investigación se basó en un enfoque cualitativo ya que se abordó la problemática condicionada en el contexto ecuatoriano desde una tipología teórica. Su propósito consistió en describir los objetos de estudio a partir de pronunciamientos emitidos por 
la Corte Interamericana de Derechos Humanos y por la Corte Constitucional del Ecuador, para ello se analizó el derecho a la verdad y la reparación integral en favor de las víctimas de graves violaciones a derechos humanos.

En cuanto a los métodos de investigación el histórico - lógico permitió caracterizar el derecho a la verdad desde su evolución dialéctica posibilitando su valoración retrospectiva en donde se destacó los cambios de época y la conformación de su marco jurídico; el analítico - sintético facultó la desintegración de los elementos del derecho a la verdad y de la reparación integral, para comprender la relación que existe entre estas variables; el inductivo - deductivo permitió la construcción de teoremas desde el análisis de casos particulares, estableciendo regularidades, generalizaciones y conclusiones (Urgilés, Erazo y Narváez, 2019).

\section{APORTES}

El surgimiento y consiguiente aplicación del derecho a la verdad por parte de los estados fue necesaria y emergente con el fin de establecer un frente a las graves violaciones de derechos humanos que venían ocurriendo en el continente americano por parte de agentes estatales quienes se extralimitaban en sus funciones con la excusa o amparo de cumplir las mismas en épocas donde la democracia se vio derrocada por gobiernos de facto que impusieron prácticas inconstitucionales contra el pueblo.

El Estado está obligado a brindar una respuesta a las víctimas de este tipo de delitos a través de una investigación oportuna y eficaz que permita descubrir que fue lo que relámete ocurrió, la identidad de los causantes de estos delitos, su judicialización debida y la aplicación de la sanción correspondiente, son los Estados de turno quienes por medio de las comisiones de la verdad creadas para el efecto investigan la verdad de lo que sucedió en los gobiernos pasados, especialmente en las épocas dictatoriales donde se vulneraron derechos humanos reconocidos plenamente con anterioridad. 
Para mayor argumentación de lo indicado en el párrafo anterior se debe tener en cuenta lo que se solicitó dentro del caso Tibi Vs. Ecuador, en el cual, los familiares y representantes del señor Daniel Tibi fundamentaron su petición bajo el precepto del derecho a la verdad colectivo, reclamando como una de las medidas de reparación que el Estado investigue y determine responsabilidades a los causantes de violaciones a derechos humanos que pesaron sobre el accionante de la causa antes mencionada, para lo cual exigieron que el resultado de la investigación sea divulgado públicamente para que la sociedad pueda conocer la verdad.

En este sentido, las comisiones de la verdad son quienes tienen la facultad de adoptar cualquier medio sea judicial o administrativo para investigar lo sucedido, frente a delitos que violentan derechos humanos fundamentales, para lo cual implementaran distintas estrategias, partiendo del relato emitido por las víctimas o sus familiares, dirigiendo así una investigación minuciosa con la finalidad de desentrañar la verdad, identificar a los responsables y sancionarlos, garantizando el acceso a la justicia, reparando de esta manera a las víctimas, a sus familiares y a la sociedad en su conjunto.

El derecho a saber la verdad debe ser catalogado como el medio idóneo de reparación integral en favor de las víctimas de este tipo de delitos, debiendo investigarse los hechos por medio de las comisiones de la verdad creadas para el efecto, evitando revictimizar a los agraviados. El reconocimiento de este derecho debe ser exigido por las víctimas de violaciones graves a derechos humanos como una medida de reparación en favor de los suyos y de la sociedad.

\section{REFERENCIAS CONSULTADAS}

1. Bernales, G. (2016). Scielo: Recuperado el 30 de Diciembre de 2019, de https://scielo.conicyt.cl/scielo.php?script=sci_arttext\&pid=S071852002016000200009 
2. Caicedo, D. (2014). Crímenes de lesa humanidad y violaciones de derechos humanos la actuación de la comisión de la verdad en Ecuador (Vol. 1). Quito, Ecuador: Corporación Editora Nacional.

3. Caso Albán Cornejo y otros Vs.Ecuador (Corte Interamericana de Derechos Humanos 22 de Noviembre de 2007).

4. Caso Bámaca Velásquez Vs. Guatemala, S/N (Corte Interamericana de Derechos Humanos 25 de Noviembre de 2000).

5. Caso Benavides Cevallos Vs. Ecuador (Corte Interamericana de Derechos Humanos 19 de Junio de 1998).

6. Caso de los Hermanos Gómez Paquiyauri Vs. Perú, S/N (Corte Interamericana de Derechos Humanos 8 de Julio de 2004).

7. Caso Heliodoro Portugal vs. Panamá, S/N (Corte Interamericana de Derechos Humanos 12 de 08 de 2008).

8. Caso Tibi Vs. Ecuador (Corte Interamericana de Derechos Humanos 7 de Septiembre de 2004).

9. Caso Zambrano Vélez y otros Vs. Ecuador (Corte Interamericana de Derechos Humanos 4 de Julio de 2007).

10. Comisión Colombiana de Juristas. (2007). Principios internacionales sobre impunidad y reparaciones. Bogotá: Opciones Gráficas Editores Ltda.

11. Comisión Interamericana de Derechos Humanos. (2014). Derecho a la verdad en América. Washington D. C.: CIDH.

12. Comite Internacional de la Cruz Roja. (2012). Protocolos adicionales a los convenios de Ginebra del 12 de agosto de 1949. Ginebra: S/E.

13. Corporación de Estudios y Publicaciones. (2012). Código Penal, concordancias. Quito, Ecuador: Corporación de Estudios y Publicaciones.

14. Corte Constitucional del Ecuador. (2018). Reparación integral análisis a partir de la jurisprudencia de la Corte Constitucional del Ecuador (Vol. 8). (A. Ruiz, P. Aguirre, D. Avila, \& X. Ron, Edits.) Quito, Ecuador. 
15. Cuya, E., \& Menschenrechtszentrum, N. (S/F). Koaga Roñeeta. Recuperado el 1 de Diciembre de 2019, de http://www.derechos.org/koaga/iii/1/cuya.html

16. Délano, M. (14 de Diciembre de 2004). El juez Guzmán procesa a Pinochet y ordena su arresto domiciliario por asesinato y secuestro. El magistrado considera que el ex dictador está en condiciones mentales para ser juzgado.

17. Durán, L. (2008). Criterios interamericanos. Revista Latinoamericana de Derechos Humanos, 29, 271.

18. Fajardo, L. (2012). Elementos estructurales del derecho a la verdad. Artículo de la Revista Civilizar Ciencias Sociales y Humanas de la Universidad Sergio Arboleda, 229-269.

19. González, D. (2008). El derecho a la verdad en situaciones de post-conflicto bélico de carácter no-internacional. En D. González. Bogotá, Colombia: S/E.

20. Guzmán Chávez, M. (2019). El principio constitucional de la tutela judicial efectiva vulnerado por la acción de nulidad de sentencias. IUSTITIA SOCIALIS, 4(7), 135-145. doi:http://dx.doi.org/10.35381/racii.v4i7.366

21. Hayner, P. (2006). Comisiones de la verdad: resumen esquemático. International Review of the Red Cross, 1-18.

22. Maculan, E., \& Pastor, D. (2013). El derecho a la verdad y su realización por medio del proceso penal. Madrid, España: Hammurabi.

23. Méndez, J. (2004). Derecho a la verdad frente a las graves violaciones a los derechos humanos. En V. Abramovich, A. Bovino, \& C. Christian, La aplicación de los tratados sobre derechos humanos en el ámbito local la experiencia de una década (págs. 517-540). Buenos Aires: Editores del Puerto.

24.Pedraza, W. (10 de Septiembre de 2008). Conferencia internacional de las comisiones de la verdad y el fortalecimiento de la democracia en el Ecuador.

25. Poveda, C. (2014). La verdad como derecho constitucional en Ecuador. Quito, Ecuador: Repositorio Institucional UASB.

26. Rivera, F. (2011). Inteligencia estratégica y Prospectiva. Quito: FLACSO, sede Ecuador. 
27. Sentencia N. ${ }^{\circ}$ 111-16-SEP-CC, 111-16-SEP-CC (Corte Constitucional del Ecuador 6 de Abril de 2016).

28. Sentencia N 068-18-SEP-CC, 1529-16-EP (Corte Constitucional del Ecuador 21 de Febrero de 2018).

29. Tamayo Vásquez, F., \& Pino Loza, E. (2019). Derechos Humanos de los niños, niñas y adolescentes en los procesos Arbitrales. IUSTITIA SOCIALIS, 4(7), 97114. doi:http://dx.doi.org/10.35381/racji.v4i7.357

30. Urgilés Urgilés, S. L., Erazo Álvarez, J. C., \& Narváez Zurita, C. I. (2019). El coaching y la productividad laboral en la Cooperativa de Ahorro y Crédito de la Pequeña Empresa Biblián Ltda. Koinonía, 423.

31. Ventura, M. (2005). La jurisprudencia de la Corte Interamericana de Derechos Humanos en materia de acceso a la justicia e impunidad. Taller regional sobre democrácia derechos humanos y estado de derecho. San José: S/E. 